\title{
Soda intake and osteoporosis risk in postmenopausal American-Indian women
}

\author{
Joy D Supplee', Glen E Duncan 2,3,*, Barbara Bruemmer ${ }^{2,3}$, Jack Goldberg ${ }^{2,4}$, \\ Yang Wen ${ }^{5}$ and Jeffrey A Henderson ${ }^{5}$ \\ ${ }^{1}$ Custom Fit Nutrition, LLC, Maple Valley, WA, USA: ${ }^{2}$ Department of Epidemiology, University of Washington \\ School of Public Health, WA, USA: ${ }^{3}$ Interdisciplinary Graduate Program in Nutritional Sciences, University of \\ Washington School of Public Health, PO Box 353410, Seattle, WA 98195, USA: ${ }^{4}$ Vietnam Era Twin Registry, \\ Seattle VA Epidemiologic Research and Education Center, Seattle, WA, USA: ${ }^{5}$ Black Hills Center for American \\ Indian Health, Rapid City, SD, USA
}

Submitted 30 March 2010: Accepted 7 0ctober 2010: First published online 4 January 2011

\begin{abstract}
Objective: Low bone mass often leads to osteoporosis and increased risk of bone fractures. Soda consumption may contribute to imbalances that lead to decreased bone mineral density (BMD) and general bone health. We examined the relationship between soda consumption and osteoporosis risk in postmenopausal American-Indian women, an at-risk population because of nutritional and other lifestyle-related factors.

Design: Cross-sectional analysis using logistic regression to examine associations between soda consumption and osteoporosis, and linear regression to examine the association between soda consumption and BMD, with and without adjustment for demographic and lifestyle factors. Quantitative ultrasound of the heel was performed to estimate BMD $\left(\mathrm{g} / \mathrm{cm}^{2}\right)$.

Setting: American-Indian communities in the Northern Plains and Southwestern USA. Subjects: A total of 438 postmenopausal American-Indian women.

Results: Women with osteoporosis were significantly older and had lower BMI, average daily soda intakes, BMD levels and use of hormones than women without osteoporosis $(P<0 \cdot 05)$. Soda consumption was not associated with increased odds of osteoporosis in either unadjusted or adjusted models $(P>0.05)$, although age (increased), BMI (decreased) and past hormone use (decreased) were all significantly associated with osteoporosis risk $(P<0 \cdot 05)$.

Conclusions: Although the present study did not find associations between soda consumption and osteoporosis risk in postmenopausal American-Indian women, analyses did confirm confounding between soda consumption and age and BMI. This suggests that any potential effects of soda consumption on bone health are largely mediated through these factors.
\end{abstract}

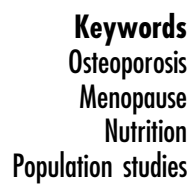

Approximately fourteen million people over the age of 50 years are expected to have osteoporosis, a chronic disease characterised by low bone mineral density (BMD), by the year $2020^{(1)}$. In turn, osteoporosis increases the risk of developing bone fractures with potentially devastating physical, mental and economic consequences ${ }^{(2,3)}$. In general, risk is highest in postmenopausal white women, individuals of small body size, the physically inactive and those who have low dietary $\mathrm{Ca}$ intake ${ }^{(3)}$. With respect to race/ethnicity, risk for osteoporosis and subsequent fracture is highest among white women, followed by Hispanic, American-Indian and Asian women, with black women having the lowest risk ${ }^{(4,5)}$.

Although data suggest that biological differences may outweigh behavioural factors in determining bone health ${ }^{(2,4-7)}$, reducing osteoporosis and fracture risk is only achievable with the use of medications and/or lifestyle modifications $^{(4)}$. For example, evidence supports the concept that physical activity and dietary Ca and vitamin D intakes are major contributors to bone health ${ }^{(1)}$. A major source of dietary Ca and vitamin D is milk. There have been some anecdotal reports, and a few scientific studies, suggesting that consumption of soft drinks, which has increased in the general population in recent years ${ }^{(8)}$, may displace milk consumption and subsequently reduce $\mathrm{Ca}$ intake ${ }^{(9-11)}$. Many cola drinks also contain high levels of phosphoric acid. One theory regarding reduced BMD in individuals who drink large amounts of cola-type beverages is that phosphoric acid may interfere with $\mathrm{Ca}$ absorption and contribute to hormonal imbalances that lead to additional 
loss of $\mathrm{Ca}^{(2,9)}$. High dietary $\mathrm{P}$ has been shown to cause bone loss in several animal studies ${ }^{(10,11)}$, and significant positive associations between consumption of these beverages and hypocalcaemia and hypercalciuria have been reported in human studies ${ }^{(10,12,13)}$. In addition, because many cola beverages also contain caffeine, which itself is known to contribute to hypercalciuria ${ }^{(14)}$, the caffeine content should also be taken into account when considering the effects of soda intake on bone health.

Many studies addressing cola consumption and bone health in humans have shown significant associations between these outcomes. For example, at least two studies found significant negative associations between cola consumption and BMD in women and adolescent girls ${ }^{(14,15)}$. However, one study considering soda consumption, not limited to colas, in white women revealed no significant association with BMD after adjusting for age, obesity and other lifestyle factors ${ }^{(16)}$. Another study found that soda intake in general was negatively associated with bone mineral accrual in adolescent boys and girls ${ }^{(17)}$.

However, whether the negative associations observed between soda intake and bone health can be attributed to milk displacement, phosphoric acid or to other lifestyle factors remains controversial. Other factors known to have an effect on bone health include BMI $\left(\mathrm{kg} / \mathrm{m}^{2}\right)$, physical activity, individual nutrients (e.g. those found in fruit and vegetables), smoking, alcohol intake, female hormones (e.g. birth control and hormone replacement therapy) and certain disease conditions, such as renal and thyroid disease ${ }^{(2)}$. Demographic factors may also affect bone health; age, race and gender are known correlates of $\mathrm{BMD}^{(2,4-6)}$.

Although some studies have examined the effects of soda consumption on bone health in adults, most have been with white women. No studies to date have examined soda intake and bone health in American-Indian women. This is a unique population in which to study the effects of soda consumption on bone health because cola beverages are the top contributors of energy intake in American-Indian women ${ }^{(18-21)}$. In contrast, milk appears as the fiftieth listed contributor to energy intake in American-Indian women and generally as part of a secondary food source, such as cheese on pizza ${ }^{(18)}$. Lactose intolerance among American Indians has been suggested as a possible reason for low intake of milk in this population ${ }^{(22-25)}$. Thus, we examined the relationship between soda consumption and measures of bone health in postmenopausal American-Indian women. We hypothesised that increased soda consumption is independently associated with decreased BMD measured at the calcaneus and with increased risk of osteoporosis in this population.

\section{Methods}

\section{Subjects}

The EARTH (Education and Research Towards Health) cohort was established to investigate how diet, activity, body size, lifestyle and cultural factors relate to the development and progression of chronic diseases in this highly susceptible population ${ }^{(26)}$. Individuals were recruited from regional centres located in Alaska, the Navajo Nation in Northern Arizona, the Plains region in Western South Dakota and the Gila River region in Southwestern Arizona. Specific methods for the EARTH study are described in detail elsewhere ${ }^{(26)}$. Briefly, baseline measurements consisted of informed consent, an intake questionnaire, several medical measurements, an audio computer-assisted self-interview diet, health and lifestyle-history questionnaire, an exit interview and individual feedback to participants.

Enrolment in the study, in accordance with tribal requirements, was open to all tribal members (a convenience sample) from the Alaska, Plains and Navajo Nation regions. A random systematic household sample was used in the Gila River centre. Eligibility criteria included: (i) being at least 18 years of age; (ii) being an American Indian or Alaska Native (AIAN) eligible for health care through the Indian Health Service; (iii) being a resident of the study area; (iv) not being pregnant at the time of baseline visit; (v) not actively undergoing cancer treatment; (vi) being able to read and understand a consent form and complete survey instruments and medical tests; and (vii) being able to complete the interview in English or in a tribal language. All participants provided written informed consent before engaging in the study.

The present study represents a secondary data analysis consisting of information gathered from the two participating Lakota Sioux reservations in Western South Dakota and the Gila River Indian Community in Arizona. This analysis was approved by the local institutional Human Subjects Division. Of the more than 5200 respondent questionnaires collected in the Plains and Gila River centres, 2843 were from women. We examined only postmenopausal women in the present study because of their greater risk for osteoporosis. Exclusions included individuals with missing or non-plausible calcaneal BMD values of $\leq 0$ or $>1 \cdot 2 \mathrm{~g} / \mathrm{cm}^{2}$, T scores $<-4$ or $>4$, and soda consumption estimated at $>24$ servings (where 1 serving is 12 fluid ounces)/d. A total of 438 women were available for analysis, of whom 287 or $66 \%$ were from the South Dakota region. Mean age was 55 (SD 11) years and directly measured BMI was $33 \cdot 3(\mathrm{sD} 7 \cdot 7) \mathrm{kg} / \mathrm{m}^{2}$. The mean T-score value of the calcaneus was $-1 \cdot 34$ (SD $1 \cdot 0$ ) and soda consumption averaged about $1 \cdot 7$ servings/d. Physical activity of any type (e.g. household, occupation, transportation and leisure) or intensity was estimated at $186 \mathrm{~min} /$ week, whereas roughly $1336 \mathrm{~min} /$ week were spent on sedentary activities.

\section{Measures}

An FFQ with culturally appropriate questions and food types was developed using a computer-assisted technology ${ }^{(27)}$. This was to reduce difficulties in respondent 
portion size selection by using realistic pictures, as well as to provide a large database of mixed dishes commonly eaten in the AIAN culture ${ }^{(26,28,29)}$. Nutrient values for 255 individual foods and beverages were assigned using Food Processor Version 10·1 (ESHA Research, Salem, OR, USA). A standard serving size was used to derive nutrients for each food or beverage, such as 12 fluid ounces for 1 serving of soda. Regarding soda intake, respondents were asked whether they had 'regular soda with caffeine (such as Coke or Mountain Dew)', 'regular soda without caffeine (such as 7-Up or root beer)', 'diet soda with caffeine' or 'diet soda without caffeine'. If the respondent answered 'yes', they were directed to answer either 'daily', 'weekly', 'monthly' or 'annually' and then pick the serving size shown in pictures representing 12 (the standard serving size), $13-24$ or $\geq 24$ ounces. Responses to these queries were transformed to common units across all participants and expressed as the number of 12-ounce standardised servings/d.

A health, lifestyle and physical activity (HLPA) questionnaire was also developed and administered at the same time as the FFQ. Major types of data collected in the HLPA included physical activity levels, medical history, reproductive history, cancer screening, over-the-counter medicine use, health status, tobacco and alcohol use and other health risk behaviours, environmental questions, family history, socio-economic status and culture/traditional lifestyle questions. A quantitative ultrasound (QUS) of the heel was performed to estimate BMD $\left(\mathrm{g} / \mathrm{cm}^{2}\right)$, which was also converted to age- and sex-standardised T scores, using a Hologic Sahara ${ }^{\circledR}$ Clinical Bone Sonometer (Bedford, MA, USA).

\section{Statistical analysis}

Analyses were performed using the STATA IC statistical software package version $10 \cdot 0$ (Stata Corp LP, College Station, TX, USA). Descriptive data were calculated using means and SD or percentages where appropriate. We used the $\chi^{2}$ test to compare categorical variables and a $t$ test or ANOVA for continuous variables between or among groups differing in osteoporosis status (see grouping in this section below). Linear regression was used to examine the association between soda consumption and BMD. Adjusted regression models were constructed to examine the associations between average daily soda consumption and BMD after controlling for age alone, BMI alone, age and BMI together, and all mediating factors (i.e. addition of physical activity level, smoking status and hormone use). Next, a dichotomous outcome variable was created using cut-off points of BMD T scores as defined by $\mathrm{WHO}^{(30)}$, representing osteoporosis $\left(\mathrm{BMD} \leq-2.5 \mathrm{~g} / \mathrm{cm}^{2}\right.$ ) and non-osteoporosis (i.e. normal $\left(\mathrm{BMD} \geq-1 \cdot 0 \mathrm{~g} / \mathrm{cm}^{2}\right)$ and osteopenia (BMD $<-1 \cdot 0$ and $\geq-2 \cdot 5 \mathrm{~g} / \mathrm{cm}^{2}$ ) combined). Logistic regression was used to examine the association between soda consumption and odds of osteoporosis. Adjusted logistic regression models were constructed to examine the associations between average daily soda consumption and odds of osteoporosis after controlling for other variables, as described above. Parallel analyses were performed to examine unadjusted and adjusted OR by the three T-score groups using ordinal logistic regression. Statistical significance was established using $\alpha=0.05$ a priori for all analyses.

\section{Results}

Results of comparisons of the descriptive characteristics of postmenopausal women with and without osteoporosis are presented in Table 1 . There were no significant differences between groups for leisure-time physical activity, daily intake of $\mathrm{P}, \mathrm{Ca}$ and vitamin $\mathrm{D}$, and smoking status (current smokers; 30\% in osteoporosis and $25.4 \%$ in non-osteoporosis groups, respectively; $P>0 \cdot 05)$. However, women with osteoporosis were significantly older and had significantly lower BMI, BMD and average daily soda consumption levels than women without osteoporosis $(P<0 \cdot 05)$. In addition, fewer women with osteoporosis reported current use of hormones $(8 \cdot 3 \%$ in osteoporosis and $9 \cdot 3 \%$ in non-osteoporosis

Table 1 Comparison of descriptive characteristics among postmenopausal American-Indian women by osteoporosist status

\begin{tabular}{|c|c|c|c|c|}
\hline \multirow[b]{2}{*}{ Predictor variables } & \multicolumn{2}{|c|}{ Osteoporosis $(n 60)$} & \multicolumn{2}{|c|}{ Non-osteoporosis (n 378) } \\
\hline & Mean & SD & Mean & SD \\
\hline Age (years) & $62 \cdot 4^{\star *}$ & $10 \cdot 4$ & $53 \cdot 9^{\star *}$ & $10 \cdot 7$ \\
\hline BMI $\left(\mathrm{kg} / \mathrm{m}^{2}\right)$ & $28 \cdot 8^{\star *}$ & $5 \cdot 7$ & $34 \cdot 0^{\star *}$ & $7 \cdot 7$ \\
\hline Soda (servings/d) & $1 \cdot 1^{*}$ & $1 \cdot 9$ & $1 \cdot 8^{*}$ & $3 \cdot 0$ \\
\hline Physical activity (min/week) & $179 \cdot 3$ & $433 \cdot 9$ & $187 \cdot 0$ & $372 \cdot 9$ \\
\hline Bone mineral density $\left(\mathrm{g} / \mathrm{cm}^{2}\right)$ & $0 \cdot 3^{\star \star}$ & 0.03 & $0 \cdot 5^{\star *}$ & 0.1 \\
\hline Phosphorus (mg/1000 kcal) & $536 \cdot 4$ & $123 \cdot 1$ & $526 \cdot 2$ & $115 \cdot 6$ \\
\hline $\mathrm{Ca}(\mathrm{mg} / 1000 \mathrm{kcal})$ & $479 \cdot 8$ & $326 \cdot 7$ & $494 \cdot 7$ & $410 \cdot 5$ \\
\hline Vitamin $D(\mu \mathrm{g} / 1000 \mathrm{kcal})$ & $3 \cdot 2$ & $4 \cdot 5$ & $2 \cdot 7$ & $2 \cdot 7$ \\
\hline
\end{tabular}

Mean values are significantly different by group: ${ }^{*} P<0.05,{ }^{* \star} P<0.0001$.

tOsteoporosis status was defined using calcaneal bone mineral density (BMD, $\mathrm{g} / \mathrm{cm}^{2}$ ) T scores; osteoporosis for BMD $\leq-2 \cdot 5$ and non-osteoporosis (normal and osteopenia combined) for BMD $>-2 \cdot 5$.

$\ddagger$ The physical activity variable represents total leisure-time activity of any intensity. 
Table 2 Unadjusted and adjusted regression coefficients among postmenopausal American-Indian women

\begin{tabular}{|c|c|c|c|c|c|}
\hline \multirow[b]{2}{*}{ Predictor variables } & \multicolumn{5}{|c|}{ Bone mineral density (calcaneus) } \\
\hline & Unadjusted & Adjusted & Adjusted & Adjusted & Adjusted \\
\hline $\begin{array}{l}\text { Soda } \\
\text { Age (vears) }\end{array}$ & $0.00702^{\star \star}$ & $\begin{array}{c}0.00235 \\
-0.00369^{\star *}\end{array}$ & $0.00572^{*}$ & $\begin{array}{c}0.00152 \\
-0.00346^{\star *}\end{array}$ & $\begin{array}{c}0.00113 \\
-0.00365^{\star *}\end{array}$ \\
\hline BMI $\left(\mathrm{kg} / \mathrm{m}^{2}\right)$ & & & $0.00356^{\star *}$ & $0.00307^{* *}$ & $0.00305^{\star *}$ \\
\hline Physical activityt & & & & & 0.00001 \\
\hline Hormones (past) & & & & & $0.03143^{*}$ \\
\hline Hormones (current) & & & & & $0.04306^{*}$ \\
\hline Smoking (past) & & & & & 0.00384 \\
\hline Smoking (current) & & & & & -0.00673 \\
\hline
\end{tabular}

${ }^{\star} P<0.05,{ }^{\star \star} P<0.0001$.

tThe physical activity variable represents total leisure-time physical activity (min/week).

Table 3 Unadjusted and adjusted OR of osteoporosist among postmenopausal American-Indian women

\begin{tabular}{|c|c|c|c|c|c|}
\hline \multirow[b]{2}{*}{ Predictor variables } & \multicolumn{5}{|c|}{ Osteoporosis status } \\
\hline & $\begin{array}{c}\text { Unadjusted } \\
\text { OR }\end{array}$ & $\begin{array}{c}\text { Adjusted } \\
\text { OR }\end{array}$ & $\begin{array}{c}\text { Adjusted } \\
\text { OR }\end{array}$ & $\begin{array}{c}\text { Adjusted } \\
\text { OR }\end{array}$ & $\begin{array}{c}\text { Adjusted } \\
\text { OR } \\
\end{array}$ \\
\hline Soda & 0.88 & 0.98 & 0.91 & 1.00 & $1 \cdot 01$ \\
\hline Age (years) & & $1 \cdot 09^{\star *}$ & & $1 \cdot 08^{\star *}$ & $1 \cdot 08^{\star \star}$ \\
\hline BMI $\left(\mathrm{kg} / \mathrm{m}^{2}\right)$ & & & $0 \cdot 88^{* *}$ & $0 \cdot 88^{* *}$ & $0 \cdot 88^{\star \star}$ \\
\hline Physical activity & & & & & $1 \cdot 00$ \\
\hline Hormones (past) & & & & & $0.30^{*}$ \\
\hline Hormones (current) & & & & & $0 \cdot 71$ \\
\hline Smoking (past) & & & & & 0.97 \\
\hline Smoking (current) & & & & & $1 \cdot 10$ \\
\hline
\end{tabular}

${ }^{*} P<0.05,{ }^{* *} P<0.0001$.

tOsteoporosis status was defined using calcaneal bone mineral density $\left(\mathrm{BMD}, \mathrm{g} / \mathrm{cm}^{2}\right) \mathrm{T}$ scores; osteoporosis for BMD $\leq-2.5$ and nonosteoporosis (normal and osteopenia combined) for BMD $>-2 \cdot 5$.

$\ddagger$ The physical activity variable represents total leisure-time physical activity ( $\mathrm{min} /$ week).

groups, respectively; $P<0 \cdot 05)$. The results across the three T-score groups (normal, $n$ 152; osteopenia, $n$ 226; osteoporosis, $n$ 60) mirrored the results using the dichotomous outcome noted above, with significant differences $(P<0.05)$ among groups for age (increasing age from normal to osteopenia to osteoporosis), BMI (decreasing BMI from normal to osteopenia to osteoporosis), soda (decreasing consumption of soda from normal to osteopenia to osteoporosis) and BMD (decreasing BMD from normal to osteopenia to osteoporosis).

Results of the linear regression models are shown in Table 2. In the unadjusted model, soda consumption was positively and significantly associated with BMD $(P<0 \cdot 0001)$. In the age-adjusted model, soda consumption was no longer significantly associated with BMD $(P>0 \cdot 05)$, whereas age was negatively associated with BMD $(P<0 \cdot 0001)$. In contrast, when adjusting for BMI only, soda consumption and BMI were both significantly and positively associated with BMD $(P<0 \cdot 05)$. However, soda consumption was no longer associated $(P>0.05)$ with BMD when adjusted for age and BMI; these variables were both significantly associated with BMD $(P<0 \cdot 0001)$. Finally, in the full model, in addition to age and BMI, past and current hormone use was positively associated with BMD $(P<0 \cdot 05)$.
There were two minor differences in the results of regression models when the sample was stratified by region. First, among women in the Northern Plains, soda was not associated with BMD in any of the regression models $(P>0 \cdot 05)$. Second, among women in the Southwest, past and current hormone use was not associated $(P>0.05)$ with BMD in the fully adjusted model, although past smoking was significantly associated $(P<0 \cdot 05)$ with BMD.

Results of the logistic regression models are shown in Table 3. In all models, soda consumption was not associated with odds of osteoporosis $(P>0 \cdot 05)$. In adjusted models, age was associated with higher odds and BMI with lower odds of osteoporosis $(P<0 \cdot 001)$. In the full model, in addition to age and BMI, the only other factor significantly associated with odds of osteoporosis was past hormone use (lower odds, $P<0 \cdot 05$ ). Results of the ordinal logistic regression models are shown in Table 4 . In contrast to the logistic regression using a dichotomous outcome, soda consumption was associated with the T-score group in the unadjusted model and in the model adjusted for BMI only (both $P<0.05$ ). In adjusted models, both age and BMI were similarly associated with the T-score group $(P<0 \cdot 001)$. In the full model, in addition to age and BMI, the only other factor significantly associated with the T-score group was past hormone use (lower odds, $P<0 \cdot 05$ ). 
Table 4 Unadjusted and adjusted OR by T-score groupt among postmenopausal American-Indian women

\begin{tabular}{|c|c|c|c|c|c|}
\hline \multirow[b]{2}{*}{ Predictor variables } & \multicolumn{5}{|c|}{ T-score group } \\
\hline & $\begin{array}{c}\text { Unadjusted } \\
\text { OR }\end{array}$ & $\begin{array}{l}\text { Adjusted } \\
\text { OR }\end{array}$ & $\begin{array}{l}\text { Adjusted } \\
\text { OR }\end{array}$ & $\begin{array}{l}\text { Adjusted } \\
\text { OR }\end{array}$ & $\begin{array}{c}\text { Adjusted } \\
\text { OR }\end{array}$ \\
\hline $\begin{array}{l}\text { Soda } \\
\text { Age (years) } \\
\text { BMI (kg/m²) } \\
\text { Physical activity } \\
\text { Hormones (past) } \\
\text { Hormones (current) } \\
\text { Smoking (past) } \\
\text { Smoking (current) }\end{array}$ & $0 \cdot 87^{*}$ & $\begin{array}{l}0.93 \\
1.06^{\star *}\end{array}$ & $\begin{array}{l}0.88^{\star} \\
0.93^{\star \star}\end{array}$ & $\begin{array}{l}0.94 \\
1.06^{\star \star} \\
0.93^{\star \star}\end{array}$ & $\begin{array}{l}0.95 \\
1 \cdot 07^{\star \star} \\
0 \cdot 93^{\star \star} \\
1 \cdot 0 \\
0 \cdot 48^{\star} \\
0.61 \\
1.08 \\
1 \cdot 08\end{array}$ \\
\hline
\end{tabular}

\section{Discussion}

In this cohort of postmenopausal American-Indian women, soda consumption was not independently associated with either BMD or increased odds of osteoporosis. On the other hand, age and BMI were both strongly associated with odds of osteoporosis (increased and decreased, respectively) in adjusted logistic regression models. Neither factor had much effect on the other. The OR for age and BMI was unchanged when each of these factors was entered alone or in combination with soda consumption. Even in the fully adjusted model, age was still associated with an $8 \%$ increased and BMI a $12 \%$ decreased odds of osteoporosis. Past hormone use was the only other factor associated with odds of osteoporosis in the fully adjusted model. Thus, both age and BMI, alone or in combination, masked any effects of other factors including soda consumption on odds of osteoporosis. Interestingly, soda consumption was significantly associated with BMD when controlling for BMI alone, in contrast to the logistic regression models using osteoporosis as the outcome measure. This difference is likely because the dichotomised osteoporosis variable is based on an age-adjusted $\mathrm{T}$ score of the raw BMD value.

The results differed somewhat when we examined OR across the three T-score groups using ordinal logistic regression. Soda consumption was significantly associated with the T-score group in the unadjusted model and in the model adjusted for BMI only, with essentially no change in the OR for soda. Unlike the logistic regression approach using a dichotomous outcome, these results suggest that BMI does not explain the association between soda consumption and the T-score group. Instead, age appears to be the major confounder because the OR for soda changes from 0.87 (significant) in the unadjusted model to 0.93 (not significant) in the model adjusted for age only, and remains essentially unchanged $(0 \cdot 94$, not significant) when adjusted for age and BMI together.

These findings are relatively consistent with previous research that shows that BMI may have a protective effect on BMD or osteoporosis risk. Bones can adjust their strength to a mechanical load by increasing their BMD or cross-sectional size ${ }^{(7,31)}$. In elderly women, a study assessing the effect of BMI on femoral neck BMD confirmed that a high BMI was protective ${ }^{(32)}$. In our analysis, increased body weight was a major factor, as evidenced by a mean BMI of roughly $34 \mathrm{~kg} / \mathrm{m}^{2}$ for the non-osteoporosis group, a value well into the obesity range. However, whether there is a threshold of BMI above which decreased measures of bone health are observed cannot be determined from our data.

A previous analysis of the Framingham osteoporosis study revealed a negative association between cola consumption, including decaffeinated colas, and BMD in women. However, our analysis was of soda in general and our findings indicated a positive association of increased soda consumption as related to higher BMI values ${ }^{(14)}$. Our findings, in fact, were more similar to a study conducted in white women revealing that, after adjusting for factors including obesity, age, physical activity, menopausal status and/or hormone use and smoking, soda intake lost significance with respect to its association with $\mathrm{BMD}^{(16)}$.

Results from the present analysis refute our initial hypothesis. Soda consumption was not independently associated with BMD nor was it associated with an increased risk of osteoporosis derived from BMD T scores in this cohort of American-Indian women. In fact, our findings indicate that, before adjusting for age, BMI and other lifestyle factors, soda consumption was significantly and positively associated with increased BMD, but not with risk of osteoporosis. However, this finding was likely almost entirely because of the confounding caused by age and increased BMI in this population. The present study not only highlights the strong effect of increased BMI on bone health, expressed as age-adjusted T-score groups based on BMD values, but also provides evidence for an association between soda consumption and higher BMI in this cohort.

Although the nutrient of interest in soda was P, soda consumption was not divided into those containing 
phosphoric acid in the original questionnaire. In the present study, we only considered soda consumption per se; however, we believe that most of the soda intake was from beverages with a high phosphoric acid content. Cola beverages, often a more popular choice, are more likely to contain phosphoric acid, including diet cola beverages, whereas non-cola beverages usually do not contain phosphoric acid, with few exceptions. Further research could include soda types consumed (i.e. those containing phosphoric acid or not). However, when we analysed the data separating soda consumption by caffeine content, the effect was not significant between groups (data not shown).

It is also noteworthy that 326 out of the original 2843 female respondents in the main data set did not answer questions regarding soda consumption and were thus excluded from further analysis. An additional twentythree respondents reported intakes of greater than twenty-four, 12-ounce servings of soda/d, raising some concern over the accuracy of reported intakes. Some plausible explanations for this are that respondents had difficulties in selecting accurate portion sizes or possibly made repeated selections because of the page-changing functionality of the computer-assisted FFQ. However, these respondents were also excluded from further analysis after data cleaning of non-plausible responses, leaving a total sample size of 438 women after other previously mentioned exclusions were made. Further, there may still be some concern as to the accuracy of soda intake in women reporting up to 24 servings/d, although it is difficult to establish a threshold for what is considered inappropriate or non-plausible soda intake.

The gold standard in the field of bone health is to measure BMD of the hip and spine using dual-energy X-ray absorptiometry (DXA). However, we performed QUS of the heel to estimate BMD instead, which may have introduced some measurement error. Nevertheless, two large independent prospective studies have shown that QUS at the heel can be used to predict future fracture risk in older women, with a gradient of risk similar to DXA measures, and hip fractures independently of $\mathrm{BMI}^{(33,34)}$. The advantages of high portability, low cost, significantly shorter scan times and a reduced exposure to radiation also made the use of QUS heel scans ideal for this epidemiological cohort study.

Although higher BMI may possibly be protective of BMD and osteoporosis risk, it is important to note the well-established associations between higher BMI and major health outcomes such as diabetes and CVD, especially in American-Indian populations. Data from the 2005 Indian Health Service indicate that $14 \cdot 2 \%$ of AmericanIndians and Alaska Natives aged $\geq 20$ years who received care from this organisation had diagnosed diabetes, with rates varying by region, from $6.0 \%$ among Alaska Native adults to a whopping $29 \cdot 3 \%$ among American-Indian adults in Southern Arizona. By comparison, data from the
2004-2006 national survey indicate that only $6 \cdot 6 \%$ of non-Hispanic white women, $7 \cdot 5 \%$ of Asian Americans, $10 \cdot 4 \%$ of Hispanics and $11 \cdot 8 \%$ of non-Hispanic black women had diagnosed diabetes ${ }^{(35)}$. Data also indicate that the death rate due to heart disease was $20 \%$ greater among American Indians and Alaska Natives than among all US races combined ${ }^{(36)}$. Finding a balance between the 'protectiveness' of BMI on bone health and its increased risk for diabetes and heart disease remains a challenge. Our findings also support the need for a more sensitive dietary instrument to detect relationships between individual nutrients and BMD among American-Indian and Alaska Native populations.

\section{Acknowledgements}

The National Cancer Institute funded the EARTH study (CA89139, J.A.H., principal investigator (PI)) and also supported the analyses (1U01 CA114642-01, D. Buchwald, PI). The contents of this manuscript are solely the responsibility of the authors and do not necessarily represent the official view of the National Cancer Institute. None of the authors declared a conflict of interest with respect to the content of this manuscript. J.D.S. designed the study, performed statistical analyses, wrote the initial draft of the manuscript and reviewed edited versions of the manuscript; G.E.D. designed the study, helped in data interpretation and edited versions of the manuscript; B.B. and J.G. helped in data interpretation and edited versions of the manuscript; Y.W. performed the statistical analyses, helped in data interpretation and edited versions of the manuscript; J.A.H. is the PI of the parent study and is responsible for data collection; he also helped in data interpretation and edited versions of the manuscript. The authors acknowledge the contributions and support of the Indian Health Service, the Cheyenne River Sioux Tribe, the Oglala Sioux Tribe and the Gila River Indian Community; Tribal Advisory Board Members including Beverley Pitman, George Ridley, Ileen Sylvester, Tim Gilbert, Fritz George, Terry Pourier and Jayme Longbrake; the staff associated with BHCAIH including Joyce Colombe, Marcia O'Leary, Betty Jarvis, Dr Patricia Nez Henderson, Dr Marie Russell, Kurt Schweigman, Bert Lewis, Wendy Lawrence, Daniel Kougl, Marie Gross, Jay Kunf, Lauri Bickle, Francine Red Willow, Arie Shiroma, Lois Bettlyoun, Mary Merrivale and Lillian Brown. They also acknowledge James Bryner and Kelly Cunningham for computer programming, and Karen Barale for reviewing a draft of the manuscript.

\section{References}

1. US Department of Health and Human Services (2004) Bone Health and Osteoporosis: A Report of the Surgeon General. Rockville, MD: DHHS, Office of the Surgeon General. 
2. Dawson-Hughes B (2006) Osteoporosis. In Modern Nutrition in Health and Disease, 10th ed., pp. 1339-1361 [M Shils, editor]. Baltimore, MD: Lippincott Williams \& Wilkens.

3. US Department of Health and Human Services, Centers for Disease Control and Prevention (2008) Nutrition for everyone: calcium and bone health. http://www.cdc.gov/ nccdphp/dnpa/nutrition/nutrition_for_everyone/bonehealth/ (accessed March 2010).

4. Pothiwala P, Evans EM \& Chapman-Novakofski KM (2006) Ethnic variation in risk for osteoporosis among women: a review of biological and behavioral factors. $J$ Womens Health (Larchmt) 15, 709-719.

5. Barrett-Connor E, Siris ES, Wehren LE et al. (2005) Osteoporosis and fracture risk in women of different ethnic groups. J Bone Miner Res 20, 185-194.

6. Araujo AB, Travison TG, Harris SS et al. (2007) Race/ethnic differences in bone mineral density in men. Osteoporos Int 18, 943-953.

7. Guglielmi G, van Kuijk C, Li J et al. (2006) Influence of anthropometric parameters and bone size on bone mineral density using volumetric quantitative computed tomography and dual X-ray absorptiometry at the hip. Acta Radiol 47, 574-580.

8. Tucker KL (2003) Dietary intake and bone status with aging. Curr Pharm Des 9, 2687-2704.

9. Fitzpatrick L \& Heaney RP (2003) Got soda? J Bone Miner Res 18, 1570-1572.

10. Heaney RP \& Rafferty K (2001) Carbonated beverages and urinary calcium excretion. Am J Clin Nutr 74, 343-347.

11. Mrdjenovic G \& Levitsky DA (2003) Nutritional and energetic consequences of sweetened drink consumption in 6- to 13-year-old children. J Pediatr 142, 604-610.

12. Fernando GR, Martha RM \& Evangelina R (1999) Consumption of soft drinks with phosphoric acid as a risk factor for the development of hypocalcemia in postmenopausal women. J Clin Epidemiol 52, 1007-1010.

13. Mazariegos-Ramos E, Guerrero-Romero F, RodriguezMoran M et al. (1995) Consumption of soft drinks with phosphoric acid as a risk factor for the development of hypocalcemia in children: a case-control study. J Pediatr 126, 940-942.

14. Tucker KL, Morita K, Qiao N et al. (2006) Colas, but not other carbonated beverages, are associated with low bone mineral density in older women: the Framingham Osteoporosis Study. Am J Clin Nutr 84, 936-942.

15. McGartland C, Robson PJ, Murray L et al. (2003) Carbonated soft drink consumption and bone mineral density in adolescence: the Northern Ireland Young Hearts project. J Bone Miner Res 18, 1563-1569.

16. Kim SH, Morton DJ \& Barrett-Connor EL (1997) Carbonated beverage consumption and bone mineral density among older women: the Rancho Bernardo Study. Am J Public Health 87, 276-279.

17. Whiting S, Healy A, Psiuk S et al. (2001) Relationship between carbonated and other low nutrient dense beverages and bone mineral content of adolescents. Nutr Res 21, 1107-1115.

18. Taylor CA, Keim KS \& Gilmore AC (2005) Impact of core and secondary foods on nutritional composition of diets in Native-American women. J Am Diet Assoc 105, 413-419.

19. Ballew C, White LL, Strauss KF et al. (1997) Intake of nutrients and food sources of nutrients among the Navajo: findings from the Navajo Health and Nutrition Survey. J Nutr 127, Suppl. 10, 2085S-2093S.
20. Lytle LA, Dixon LB, Cunningham-Sabo L et al. (2002) Dietary intakes of Native American children: findings from the pathways feasibility study. J Am Diet Assoc 102, $555-558$

21. Wharton CM \& Hampl JS (2004) Beverage consumption and risk of obesity among Native Americans in Arizona. Nutr Rev 62, 153-159.

22. Johnson JD, Simoons FJ, Hurwitz R et al. (1977) Lactose malabsorption among the Pima Indians of Arizona. Gastroenterology 73, 1299-1304.

23. Johnson JD, Simoons FJ, Hurwitz R et al. (1978) Lactose malabsorption among adult Indians of the Great Basin and American Southwest. Am J Clin Nutr 31, 381-387.

24. Newcomer AD, Gordon H, Thomas PJ et al. (1977) Family studies of lactase deficiency in the American Indian. Gastroenterology 73, 985-988.

25. Newcomer AD, Thomas PJ, McGill DB et al. (1977) Lactase deficiency: a common genetic trait of the American Indian. Gastroenterology 72, 234-237.

26. Slattery ML, Schumacher MC, Lanier AP et al. (2007) A prospective cohort of American Indian and Alaska Native people: study design, methods, and implementation. $\mathrm{Am} \mathrm{J}$ Epidemiol 166, 606-615.

27. Edwards SL, Slattery ML, Murtaugh MA et al. (2007) Development and use of touch-screen audio computerassisted self-interviewing in a study of American Indians. Am J Epidemiol 165, 1336-1342.

28. Hu FB, Rimm E, Smith-Warner SA et al. (1999) Reproducibility and validity of dietary patterns assessed with a food-frequency questionnaire. Am J Clin Nutr 69, 243-249.

29. Marks GC, Hughes MC \& van der Pols JC (2006) Relative validity of food intake estimates using a food frequency questionnaire is associated with sex, age, and other personal characteristics. J Nutr 136, 459-465.

30. Kanis JA (1994) Assessment of fracture risk and its application to screening for postmenopausal osteoporosis: synopsis of a WHO report. WHO Study Group. Osteoporos Int 4, 368-381.

31. Cvijetic S \& Korsic M (2004) Apparent bone mineral density estimated from DXA in healthy men and women. Osteoporos Int 15, 295-300.

32. Barrera G, Bunout D, Gattas V et al. (2004) A high body mass index protects against femoral neck osteoporosis in healthy elderly subjects. Nutrition 20, 769-771.

33. Hans D, Dargent-Molina P, Schott AM et al. (1996) Ultrasonographic heel measurements to predict hip fracture in elderly women: the EPIDOS prospective study. Lancet 348, 511-514.

34. Bauer DC, Gluer CC, Cauley JA et al. (1997) Broadband ultrasound attenuation predicts fractures strongly and independently of densitometry in older women. A prospective study. Study of Osteoporotic Fractures Research Group. Arch Intern Med 157, 629-634.

35. National Diabetes Information Clearinghouse, National Institute of Diabetes and Digestive and Kidney Diseases, National Institues of Health (2008) National Diabetes Statistics, 2007: Race and Ethnic Differences in Prevalence of Diagnosed Diabetes. NIH Publication no. 08-3892. Washington, DC: NIH.

36. US Department of Health and Human Services, Centers for Disease Control and Prevention (2008) American Indian and Alaska Native Heart Disease and Stroke Fact Sheet. http://www.cdc.gov/dhdsp/library/fs_aian.htm/ (accessed March 2010). 